\title{
Quantification of the use of eponyms in two Latin American congresses of anatomy
}

\author{
Jorge Eduardo Duque Parra ${ }^{1,2}$, John Barco Ríos ${ }^{1}$, Juan Fernando Vélez García ${ }^{3}$ \\ ${ }^{1}$ Department of Basic Sciences, Faculty of Health Sciences, Universidad de Caldas, Manizales, ${ }^{2}$ Medicine Program, Department of Basic Sciences, \\ Universidad de Manizales, Manizales, ${ }^{3}$ Department of Animal Health, Faculty of Veterinary Medicine and Zootechnics, Universidad del Tolima, Ibagué, \\ Colombia
}

\begin{abstract}
Eponyms have been part of medical language for many centuries, have put down powerful cultural roots, and continue to be used mainly in the language of medical specialties. The problem with eponymy is that it does not provide any relevant information about what is being studied, which hinders learning and generates communication problems. Ten oral presentations were randomly evaluated, as were all poster presentations made at the II Peruvian Congress on Morphological Sciences and the XV Ibero-Latin American Symposium on Anatomical, Histological, and Embryological Terminology, held in March of 2018 in Lima, Peru. This was done in order to quantify eponym use. Of the 10 oral presentations randomly selected, the eponym use was identified in six (60\%). Of the 33 poster presentations made, six (18.18\%) used eponyms. In conclusion, eponyms continue to be used indiscriminately in the language of the morphological sciences.
\end{abstract}

Key words: Eponymy, Anatomical terminology, Medical sciences

Received June 10, 2019; Revised August 19, 2019; Accepted September 3, 2019

\section{Introduction}

During the observance of the XIII Global Anatomist Conference which took place in Rio de Janeiro (Brazil) in 1989, the International Federation of Associations of Anatomists (IFAA) created a new association, called the Federative International Committee of Anatomical Terminology (FICAT) [1]. The FICAT which was charged with the review, correction, and permanent refinement of International Anatomical Terminology so as to unify the language employed by morphological science professionals (a group which include anatomists, histologists, and embryologists). The names created for the various anatomical structures were designed with

\footnotetext{
Corresponding author:

Juan Fernando Vélez García (1)

Department of Animal Health, Faculty of Veterinary Medicine and Zootechnics, Universidad del Tolima, Barrio Altos de Santa Helena, Ibagué, Colombia

Tel:+57-3117559042, Fax:+57-8-2771212, E-mail: jfvelezg@ut.edu.co
}

morpho-functional logic in mind: they were designed such that their morphological structure characteristics would relate to the function they served [2]. The language utilized by the FICAT complies with descriptive, topographical, informative, didactic, and communicative criteria, unlike that which occurs in literary language, which accomplishes more esthetic or recreational goals [3]. It is important, since anatomy is a course where the students should understand the detailed structure of the body [4], therefore the use of the names established by the FICAT would facilitate learning and communication between students and health professionals.

Eponyms, those terms assigned to determined anatomical structures with the name of the individual who initially described them, have formed part of medical language for countless centuries. For this reason, they have become deeply entrenched in the culture to the point where they continue to be used heavily, principally in the language employed in medical specialties. The problem with eponymy is that it does not provide any relevant information [5] about the subject of study. Thus, its use is incoherent, arbitrary and heavily in-

\section{Copyright (C) 2020. Anatomy \& Cell Biology}

This is an Open Access article distributed under the terms of the Creative Commons Attribution Non-Commercial License (http://creativecommons.org/licenses/by-nc/4.0/) which permits unrestricted non-commercial use, distribution, and reproduction in any medium, provided the original work is properly cited. 
fluenced by geography and the local culture of the time [6]. The adjudication of eponyms presents a certain degree of randomization [7] and injustice [7, 8]. In addition to the fact that it represents a gaffe in the logic of contemporary thought [8]. However, although eponymy was eliminated from Anatomical terminology since $1933[9,10]$, it remains a controversial issue $[11,12]$ and a major obstacle that still it is not possible to overcome.

The Ibero-Latin American Symposium on Anatomical, Histological, and Embryological Terminology (SILAT, acronym in Spanish), is a committee of experts created in 2009 by the Pan-American Anatomy Association (APA, acronym in Spanish). There, anatomists from the majority of Latin American countries meet to study, analyze, translate, adapt, disseminate and promote international morphological terminology [13]. Its objective is to unify in our region the terms assigned to morphological structures to achieve a common scientific language that facilitates learning and communication between professionals [13]. Thus, the SILAT must ensure that in any type of scientific dissemination, whether oral or written, the correct use of Terminologia anatomica (International Anatomical Terminology) respected and that no eponyms or toponyms are used. Such terms can only have historical interest [14] that could be published in books on the history of morphological science, in dictionaries of regionalisms or eponyms [15], since from the morphological point of view they cannot they have descriptive or informative value $[14,16]$. Instead, said terms impede communication and the teachinglearning process. Anatomical eponyms are unofficial terms, and as such, should not be used in International Anatomical Terminology. In the Terminologia Anatomica's official book edited by the FICAT, 398 eponyms were included in a special section $[14,17]$ as a historical record thereof.

The aim of the present study was to describe and quantify the use of eponyms during the development of two Latin American congresses of anatomy.

\section{Materials and Methods}

Ten randomly selected oral presentations were evaluated, as were all poster presentations made in the II Peruvian Conference on Morphological Sciences and the XV Ibero-Latin American Symposium on Anatomical, Histological, and Embryological Terminology, which were held in March of 2018 in Lima, Peru. This was done in order to calculate the percentage of eponym use in the two presentation types, both in
Table 1. Use of eponyms in two Latin American congresses of anatomy

\begin{tabular}{lccc}
\hline & Randomly selected & Use of eponyms & Use of eponyms (\%) \\
\hline Oral presentations & 10 & 6 & 60 \\
Poster & 33 & 6 & 18.18 \\
\hline
\end{tabular}

title and content and throughout the conference. Those studies, which focused on eponym use from historical, associated analysis, chemical coloration name, pathological entity name, biological rule name, medical doctrine, and study parameter points of view, were excluded.

\section{Results}

Of the ten randomly selected oral presentations, the use of distinct eponyms was identified in six (60\%). These included: Sylvian fissure, Broca's area, Rolando's fissure, Heschl's gyrus, eye of Horus, foramina of Monro, Sylvian aqueduct, Vieussens valve, foramina of Magendie, Islets of Langerhans, Andersch's ganglion, nerve of Wrisberg, Golgi tendon organ, Poggiolini's quadrilateral, Camper's fascia, and Scarpa's fascia. Of the 33 poster presentations, six (18.18\%) used eponyms, which included the following: recurrent artery of Heubner, spiral valves of Heister, Sertoli cells, Leydig cells, Jaffe's nerve, and the risorius of Santorini (Table 1).

\section{Discussion}

Nearly one fifth of the poster presentations $(18,18 \%)$ made during the II Peruvian Conference on Morphological Sciences and the XV Ibero-Latin American Symposium on Anatomical, Histological, and Embryological Terminology in 2018, included eponymous terms in their investigations, while over half (60\%) of the randomly-chosen oral conferences also used eponyms to name certain anatomical structures. Possibly, the greater use of eponyms during oral presentations is due to the fact that they are not previously reviewed by the referees of the event, so that the speaker feels free to use his routine anatomical language more comfortably, the one who learned from his teachers and traditional anatomy textbooks. However, it is not justifiable that this type of works has been accepted and presented in the most representative event of Peru in the anatomical field, and much less during the event that brings together the committee of experts of the SILAT that ensures the correct use of anatomical language.

It is fundamental that all scientific investigations in the field of the morphological sciences correctly employ Interna- 
tional Anatomical Terminology, since this way any morphological message or concept emitted could be received with greater clarity and lower probability of error by those present. After all, the purpose of language is clear communication, within the framework of a network of shared knowledge [18]. Those designations contained in the Anatomical Terminology Committee's official book were designed with the use of both an analytical method and adequate reasoning. This was performed in this way, so as to create well-structured morphological language [19], in which each term intrinsically contains relevant information regarding the morphological characteristics of the structure and function thereof [2]. Thus facilitating communication and learning.

The abolition of eponyms from morphological language has proven difficult, given that their long-term use has rooted them firmly in textbooks, scientific manuscripts $[6,8]$, and conferences in general, including those mentioned herein. The cause of this rooting is possibly due to the active influence exerted by two types of actors, the professors who teach anatomy and the editors of textbooks and magazines specialized in the subject. These actors, perhaps due to ignorance of International Anatomical Terminology, they continue to encourage the use of an obsolete terminology loaded with eponyms, both in classrooms and their clinical-surgical practice and in published books and scientific papers. In addition to the above, the resistance of many medical sciences professionals, especially in the clinical area, to accept changes in terminology should be mentioned, even though they know that these improve international communication [20]. However, if scientists and experts in the area of morphology do not comply with the provisions established by the FICAT regarding correct terminology use, what can be expected of professionals who do not belong to the specialized field of anatomical structure? This situation could be interpreted as a kind of attack from within the SILAT on the Anatomical Terminology Committee, which would cause a return to the indiscriminate and proliferative use of terms, among these, eponyms [19]. The result of this resistance and apathy towards change is that many professionals linked to teaching and anatomical research continue to use the eponyms during the teachinglearning process and in their scientific publications [8], which perpetuates the problem. Hence, in the traditional language of morphological sciences, the eponyms remain prolific and resist extinction $[11,12]$.

Eponyms use in morphological language, rather than make us think of a particular anatomical structure, only leads us to recall the name of some historical person who discovered or described some important detail of the anatomy, but does not provide any information which would allow for orientation or knowledge of the specific structure mentioned. Thus, eponyms should be entirely relegated to another field of study, such as the history of medicine, which would permit the preservation of a historical memory of those individuals who made important contributions to morphological knowledge. Alternatively, they might be employed in dictionaries of regionalisms [15], and even as anecdotes. What must not continue to occur is that eponyms be used within the descriptive language of morphology, given that their indiscriminate use hinders communication between medical science professionals and leads to confusion [5]. This occurred partially in the II Peruvian Conference on Morphological Sciences that took place in March of 2018 in Lima, Peru, and at the XVIII Congress of the International Federation of Associations of Anatomists, which took place in August of 2014 in Beijing, China [19].

When comparing these results with those obtained by this same research team, which analyzed the situation presented at the 18th Congress of International Federation of Associations of Anatomists [19], there is a significant reduction in the use of eponyms during randomly selected oral presentations, which went from $100 \%$ in the congress held in Beijing (China) in 2014, to 60\% in the congress held in Lima (Peru) in 2018. While in the presentations in poster mode there was a significant increase in the use of eponyms, as it went from $2.33 \%$ in China, to $18.18 \%$ in Peru.

The above raises the need to reinforce in all fields the correct use of Anatomical terminology in the new generations of students and health professionals, which will prevent the eponyms from being used outside the classroom in the near future [21], and simultaneously be reflected in a decrease in learning problems and academic failure $[22,23]$. Most importantly, this will permit clearer and more precise communication between professionals in these areas of knowledge $[8,24]$.

\section{Conclusion}

Eponyms continue to be used indiscriminately in the language of the morphological sciences (which include anatomy, histology, and embryology). This fact it's reflected in the anatomy textbooks, in scientific manuscripts published in specialized journals on the subject and in keynote lectures presented at the various national and international congresses. In general, the percentage of use of eponyms is high in medi- 
cal and morphological sciences professionals, an error attributable to the general ignorance of International Anatomical Terminology.

\section{ORCID}

Jorge Eduardo Duque Parra:

http://orcid.org/0000-0002-1432-6381

John Barco Ríos: http://orcid.org/0000-0002-6844-8624

Juan Fernando Vélez García:

http://orcid.org/0000-0003-1517-2916

\section{Author Contributions}

Conceptualization: JEDP, JBR, JFVG. Data acquisition: JEDP, JBR, JFVG. Data analysis or interpretation: JEDP, JBR, JFVG. Drafting of the manuscript: JEDP, JBR, JFVG. Critical revision of the manuscript: JEDP, JBR, JFVG. Approval of the final version of the manuscript: all authors.

\section{Conflicts of Interest}

No potential conflict of interest relevant to this article was reported.

\section{References}

1. Hernández RF. Roots of the Ibero-Latin American Terminology Symposium. Arch Anat Costa Rica 2009;4:27.

2. Ávila RE, Samar ME, Acevedo R, Barioglio C. The plant cell as a didactic instrument for understanding mitosis in the animal cell. Arch Anat Costa Rica 2009;4:51.

3. Araujo J. Reflections on current medical language: the eponyms and abbreviations. The reasons of its existence and the main problems that raise its use. Rev Biosalud 2017;16:93-104.

4. Farrokhi A, Soleymaninejad M, Ghorbanlou M, Fallah R, Nejatbakhsh R. Applied anatomy, today's requirement for clinical medicine courses. Anat Cell Biol 2017;50:175-9.

5. Duque Parra JE, Barco Rios J, Duque Quintero N. Refining the anatomical terminology: opening and foramen, two similarities and redundancy. Int J Morphol 2012;30:1497-9.

6. Vásquez B, del Sol M. The terminologia histologica in the medical sciences. Int J Morphol 2014;32:375-80.

7. Woywodt A, Matteson E. Should eponyms be abandoned?: yes. BMJ 2007;335:424.

8. Duque-Parra JE, Barco-Ríos J, Dávila-Alzate N. Eponyms in medical sciences: historical errors that cause injustices. Rev Fac Med 2018;66:87-90.

9. Cruz GR, Cruz CF. Suggestions for establishing a dictionary of anatomical, embryological and histological eponyms. Arch Anat Costa Rica 2009;4:28.

10. Duque-Parra JE, Llano-Idárraga JO, Duque-Parra CA. Reflections on eponyms in neuroscience terminology. Anat Rec B New Anat 2006;289:219-24.

11. Olry R. Anatomical eponyms, part 1: to look on the bright side. Clin Anat 2014;27:1142-4.

12. Olry R. Anatomical eponyms, Part 2: the other side of the coin. Clin Anat 2014;27:1145-8.

13. Losardo RJ, Prates NE, Arteaga-Martínez M, Cabral RH, GarcíaPeláez MI. International morphological terminology: more than anatomy, histology and embryology. Int J Morphol 2015;33:400-7.

14. Abdala P. Neuroanatomical eponyms in Revista de Neurología on-line. Rev Neurol 2007;45:201-4.

15. Cruz Gutiérrez R, Rodríguez Torres A, Prates JC, Jorge Losardo $\mathrm{R}$, Valverde Barbato N. Ibero Latin American Symposiums on Terminology: anatomy, histology and embryology. Int J Morphol 2010;28:333-6.

16. Tamayo-Orrego L, Duque-Parra JE. Axonal nodules? Replica. Rev Neurol 2007;45:191-2.

17. Federative Committe on Anatomical Terminology (FICAT). Terminologia Anatomica: International Anatomical Nomenclature. Stuttgart: Thieme; 1998.

18. Churchland PM. Matter and consciousness: contemporary introduction to the philosophy of the mind. Barcelona: Gedisa; 1999.

19. Duque Parra JE, Barco Rios J, Vélez García JF. Eponyms prevalence in publications and presentations at the 18th Congress of International Federation of Associations of Anatomists 2014. Int J Morphol 2017;35:525-9.

20. Warwick R. The future of Nomina Anatomica: a personal view. Anat Rec 1978;190:1-3.

21. Montemayor Flores BG, Herrera Vázquez I, Soto Paulino A. Analysis of the use of the Anatomical Terminology Between Students of Anatomy Courses at the Faculty of Medicine of the Universidad Nacional Autónoma de México. Int J Morphol 2016; 34:1280-4.

22. Babibski MA, Sgrott EA, Luz HP, Brasil FB, Chagas MA, AbiduFigueiredo M. The relationship of the students with corpse in the practical study of anatomy: the reaction and influence in the learning. Int J Morphol 2003;21:137-42.

23. Silva Ortiz SR, Torres Merchán NY. Meaning of learning and teaching anatomy: contributions from students' perceptions. Zona Próxima 2012;17:24-37.

24. Duque Parra JE, Barco Ríos J, Aguirre Cardona VE. From the terminology based on eponyms in surgery, to the international anatomical terminology: a great abyss that can be avoided. Int J Med Surg Sci 2014;1:253-6. 